\title{
Exploration of temperature and shelf-life dependency of the therapeutically available Insulin Detemir
}

\author{
Oritsegidenene Beji ${ }^{\mathrm{a}, 1}$, Richard B. Gillis ${ }^{\mathrm{b}, 1}{ }^{*}$, Vlad Dinu $^{\mathrm{a}, \mathrm{c}}$, Shahwar I. Jiwani ${ }^{\mathrm{b}}$, Philemon Gyasi-Antwi ${ }^{\mathrm{b}}$, \\ Ian D. Fisk ${ }^{a}$, Andrew Meal ${ }^{b}$, Paul S. Morgan ${ }^{d}$, Stephen E. Harding ${ }^{\text {a,c,e }}$, Sha Huang ${ }^{a}$, Giulia Agugini ${ }^{f}$, \\ Federica Fedele ${ }^{g}$, Gary G. Adams ${ }^{\mathrm{b}}, *$ \\ ${ }^{a}$ University of Nottingham, School of Biosciences, Sutton Bonington Campus, Leicestershire, UK \\ ${ }^{\mathrm{b}}$ University of Nottingham, School of Health Sciences, Faculty of Medicine and Health Sciences, Queens Medical Centre, Clifton Boulevard, Nottingham, UK \\ c University of Nottingham, National Centre for Macromolecular Hydrodynamics, Sutton Bonington Campus, Leicestershire, UK \\ d University of Nottingham, School of Medicine, Faculty of Medicine and Health Sciences, Queens Medical Centre, Clifton Boulevard, Nottingham, UK \\ e Universitetet I Oslo, Postboks 6762, St. Olavs plass, 0130 Oslo, Norway \\ ${ }^{\mathrm{f}}$ University of Pavia, Department of Drug Sciences, Pavia, Italy \\ ' University of Salento, Piazzetta Tancredi 7, 73100 Lecce, Italy
}

\section{A R T I C LE IN F O}

\section{Keywords}

Insulin

Temperature

Shelf-life

Mass-spectrometry

Light scattering

Viscosity

\begin{abstract}
A B S T R A C T
Purpose: Insulin, in typical use, undergoes multiple changes in temperature; from refrigerator, to room temperature, to body temperature. Although long-term storage temperature has been well-studied, the short term changes to insulin are yet to be determined. Insulin detemir (IDet) is a clinically available, slow-acting, synthetic analogue characterised by the conjugation of a C14 fatty acid. The function of this modification is to cause the insulin to form multi-hexameric species, thus retarding the pharmacokinetic rate of action. In this investigation, the temperature dependence properties of this synthetic analogue is probed, as well as expiration.

Methods: Dynamic light scattering (DLS) and viscometry were employed to assess the effect of temperature upon IDet. Mass spectrometry was also used to probe the impact of shelf-life and the presence of certain excipients.

Results: IDet was compared with eight other insulins, including human recombinant, three fast-acting analogues and two other slow-acting analogues. Of all nine insulins, IDet was the only analogue to show temperature dependent behaviour, between $20^{\circ} \mathrm{C}$ and $37{ }^{\circ} \mathrm{C}$, when probed with non-invasive backscatter dynamic light scattering. Upon further investigation, IDet observed significant changes in size related to temperature, direction of temperature (heated/cooled) and expiration with cross-correlation observed amongst all 4 parameters.

Conclusions: These findings are critical to our understanding of the behaviour of this particular clinically relevant drug, as it will allow the development of future generations of peptide-based therapies with greater clinical efficacy.
\end{abstract}

\section{Introduction}

The therapeutic applicability of a biologically active peptide is contingent on delivering it at its site of action within a suitable timeframe. Peptide and protein drug delivery is connected with several problems [29]. Peptides, prone to enzymatic breakdown and poor penetration through mucosal membranes, must be administered by injection. Additionally, most peptides have a short half-life within the circulation and must be progressively released into the bloodstream to have a sustained effect.

Insulin is a ubiquitous example of a pharmaceutical protein used in the treatment of diabetes. The main purpose of insulin therapy is to mirror standard physiological insulin secretion through basal-bolus administration [13]. In a healthy individual, pancreatic $\beta$-cells continuously excrete insulin to maintain plasma glucose levels around 4-6 mM. In patients diagnosed with diabetes mellitus this mechanism is impaired and tight glucose control is imperative to reduce the risks of hypoglycaemic and hyperglycaemic episodes [12]. However, studies have shown that normal human insulin (as well as porcine and bovine insulins) and intermediate-acting insulins like NPH have high variability in terms of pharmacodynamic and pharmacokinetic behaviour in vivo preceding poor glycaemic control $[11,23]$. Long acting insulin analogues such as degludec, glargine and detemir have displayed negli-

\footnotetext{
* Corresponding authors.

E-mail addresses: richard.gillis@nottingham.ac.uk (R.B. Gillis); gary.adams@nottingham.ac.uk (G.G. Adams)

1 These authors contributed equally.
} 
gible variability, therefore lower risks of nocturnal hypoglycaemia $[7,18]$, although some studies have disputed this claim [17].

Insulin detemir (IDet) is a long-acting, water-soluble, insulin analogue that differs structurally from human insulin in two respects: the attachment of a 14-carbon fatty acid side chain to LysB29 and the removal of ThrB30 [10]. The structure of IDet is shown in Fig. 1. These modifications protract insulin activity via self-association at the injection site and reversible binding to albumin; only the free monomeric fraction of the molecule can bind to target insulin receptors $[10,16,22,28]$.

In this investigation, we show for the first time that insulin detemir is the only analogue that exhibits high temperature dependency. Shelf-life dependence were also investigated as well as interactions between these parameters. Although long-term shelf-life/temperature studies have been performed previously $[2,6,21,27]$, to the authors' knowledge, this is the first time short-term temperature profiles of insulin have been investigated.

\section{Materials and methods}

\subsection{Insulin}

Insulin detemir (IDet), trademarked as Levemir ${ }^{\circledR}$ and manufactured by Novo Nordisk, was obtained as $3 \mathrm{~mL}$ vials, $100 \mathrm{U} / \mathrm{mL}(14.2 \mathrm{mg} / \mathrm{mL})$, for FlexTouch ${ }^{\circledR}$ pens, as a gift from the Independent Diabetes Trust. IDet excipients list includes $65.4 \mu \mathrm{g} / \mathrm{mL}$ zinc, $2.06 \mathrm{mg} / \mathrm{mL} \mathrm{m}$-cresol, $16.0 \mathrm{mg} / \mathrm{mL}$ glycerol, $1.80 \mathrm{mg} / \mathrm{mL}$ phenol, $0.89 \mathrm{mg} / \mathrm{mL} \mathrm{Na}{ }_{2} \mathrm{HPO}_{4} \cdot 2 \mathrm{H}_{2} \mathrm{O}$ and $1.17 \mathrm{mg} / \mathrm{mL} \mathrm{NaCl}$. $\mathrm{HCl}$ and $\mathrm{NaOH}$ may have been added by the manufacturer to adjust $\mathrm{pH}$ to 7.4 [20]. These preparations included expired samples $(2013,2015,2016,2017)$ as well as an in-date batch (2020). While not in use, all IDet preparations were refrigerated at $\sim 5^{\circ} \mathrm{C}$. All experiments involving expiry of samples were carried out over a 4 month period in Summer 2018.

Eight other in-date insulins were also screened to assess temperature dependence, but only for single dose concentrations. These were Human Recombinant (Novorapid $₫$, Novo Nordisk), Bovine and Porcine (Hypurin $\AA$, Wockhardt), Aspart (Actrapid $\AA$, Novo Nordisk), Glulisine (Apidra ${ }^{\circledR}$, Sanofi), Lispro (Humalog $\AA$, Lilly), Glargine (Lantus ${ }^{\circledR}$, Sanofi) and Degludec (Tresiba ${ }^{\circledR}$, Novo Nordisk).

\subsection{Dynamic light scattering}

DLS was used as a high-throughput method to monitor the change in insulin behaviour (indicated by the hydrodynamic radius) at different temperatures. All nine insulins were analysed at three temperatures (20.0, 28.0, $\left.37.0^{\circ} \mathrm{C}\right)$ using a Zetasizer NanoZS (Malvern Panalytical, Malvern, UK) with a non-invasive back scatter (NIBS) angle of $173^{\circ}$. The temperature was set to equilibrate for $180 \mathrm{~s}$ after every temperature change and three readings (11 sub-repeats of $10 \mathrm{~s}$ correlator detection) were taken and averaged. Zetasizer software v6.2 was used to obtain light scattering data. The dispersant viscosity at $20.0{ }^{\circ} \mathrm{C}$ was used, and the software was allowed to assume the viscosity at each tempera-

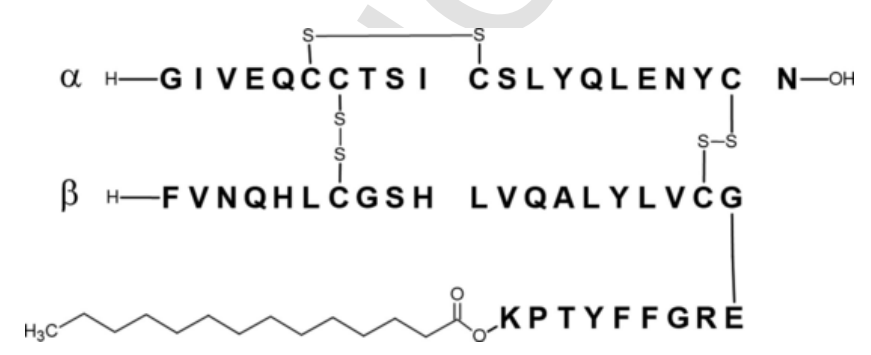

Fig. 1. Primary amino acid sequence of insulin Detemir. 21 amino acids in $\alpha$ chain, 29 amino acids in $\beta$ chain, stabilised by three disulphide bonds (-S-S-, 1 intra, 2 inter) and conjugated with a C14 fatty acid on the terminal Lysine (K). ture analysed based on built-in polynomial temperature-viscosity curves. After it was determined that IDet behaved differently to the other insulins, the different batches were assayed at every $1{ }^{\circ} \mathrm{C}\left(20.0-37.0{ }^{\circ} \mathrm{C}\right)$, both increasing and decreasing temperature trend, and number of replicates increased to 6, with the first measurement deleted to account for temperature equilibration.

Sealed polystyrene disposable cuvettes (Sartedt AG \& Co., Germany) were used to load the sample into the instrument. A $1 \mathrm{~mL}$ syringe with a Luer-locked $0.8 \mathrm{~mm} \times 40 \mathrm{~mm}$ needle (BD Microlance ${ }^{\mathrm{TM}}$ 3) was used to extract the insulin and load into the cuvette. Care was taken to prevent excessive shear stress.

\subsection{Sedimentation velocity}

IDet (2020, in-date batch) was analysed using sedimentation velocity in an analytical ultracentrifuge (Optima XL-I, Beckman Coulter, Palo Alto, USA). $390 \mu \mathrm{L}$ of each sample was loaded into centrifuge cells, each assembled from two sapphire windows, $12 \mathrm{~mm}$ aluminium-epoxy resin 2-channel centrepiece, and aluminium housing. $400 \mu \mathrm{L}$ buffer was injected into the reference side. Each cell was run in a balanced 8-hole rotor at a speed of $40000 \mathrm{rpm}(127 \mathrm{000 \textrm {g }}$ ) for $8 \mathrm{~h}$ using Rayleigh Interference optics scanning every $2 \mathrm{~min}$. Data were analysed using SEDFIT [24].

\subsection{Density measurement}

The density of IDet samples per expiry date was measured for each concentration between $20.0{ }^{\circ} \mathrm{C}$ ( $\sim$ room temperature) and $37.0^{\circ} \mathrm{C}$ ( $\sim$ body temperature) at 20.0, 25.0, 30.0, 35.0, $37.0\left( \pm 0.00005^{\circ} \mathrm{C}\right)$ using a DMA 5000 oscillating capillary density meter (Anton Paar GmbH, Graz, Austria).

\subsection{Viscometry}

IDet solutions were analysed at the same temperatures 20.0, 25.0, 30.0, 35.0, $37.0\left( \pm 0.05^{\circ} \mathrm{C}\right)$ using an AMVn rolling ball viscometer (Anton Paar $\mathrm{GmbH}$, Graz, Austria) equipped with a 6 d.mm silanised capillary and 5 d.mm steel ball. 14 replicates $\left(4 \times 70^{\circ}, 4 \times 60^{\circ}, 6 \times 50^{\circ}\right)$ of 5 serially diluted concentrations were made for each temperature and 3 batches. The specific viscosity $\eta_{s p}$ was obtained using the following equation:

$\eta_{s p}=\frac{\eta-\eta_{0}}{\eta_{0}}$

where $\eta$ is the dynamic viscosity (taking into account the previously measured density) and $\eta_{0}$ the dynamic viscosity of the solvent. A concentration $(c)$ series fitted to the following polynomial model, simplified to the second order, yielded the intrinsic viscosity $[\eta]$, and regression coefficient $k$ values: $[4,15]$

$\eta_{s p}=[\eta] c+k([\eta] c)^{2}$

\subsection{Gas chromatography coupled to mass spectrometry}

A Trace 1300 series Gas Chromatograph coupled with single-quadrupole mass spectrometer (Thermo-Fisher Scientific, Hemel Hempstead, UK) was used. Samples were incubated at $37.0^{\circ} \mathrm{C}$ for $20 \mathrm{~min}$ with intermittent agitation. Solid phase microextraction (SPME) fibre (50/ $30 \mu \mathrm{m}$ DVB/CAR/PDMS, Supelco, Sigma Aldrich, UK) was used to extract for $40 \mathrm{~min}$, with a desorption time of $1 \mathrm{~min}$. Splitless mode was used, and a constant carrier pressure of 18 psi was applied. Separation was carried out by a ZB-WAX capillary gas chromatography column (length $30 \mathrm{~m}$, internal diameter $1 \mathrm{~mm}, 1.00 \mu \mathrm{m}$ film thickness). The column temperature was initially at $40.0{ }^{\circ} \mathrm{C}$ for $2 \mathrm{~min}$, then in- 
creased by $6.0{ }^{\circ} \mathrm{C}$ every minute up until $250.0^{\circ} \mathrm{C}$, held for $5 \mathrm{~min}$. Full scan mode was chosen to measure volatile compounds (mass range from 20 to $300 \mathrm{Da}$ ). Volatiles were identified by comparison of each mass spectrum with the spectra from the NIST Mass Spectral Library.

Due to the very high concentrations of phenol and m-cresol in the insulin formulation, a 1 in 20 dilution was required to achieve acceptable signal, and not overload the column. Similarly, availability of IDet preparations limited sample volumes and only batches 2020, 2017, 2016 and 2015 were analysed.

\subsection{Statistical analysis}

Student t-tests (2-tailed) were performed on the comparative DLS study, for all nine insulins, using the built-in MS-Excel function (Office 2013). Significance was probed for individual insulins between 20 and $28{ }^{\circ} \mathrm{C} ; 28$ and $37{ }^{\circ} \mathrm{C} ; 20$ and $37^{\circ} \mathrm{C}$, but not for inter-insulin differences as this was beyond the scope of the investigation. $\mathrm{p} \leq 0.05$ and $\leq 0.005$ were used to assess level of significance.

A multiple regression general linear model (MANOVA) was performed on the comprehensive IDet DLS dataset using SPSS v23 (IBM). Controlled variables included temperature, direction (ascending/descending) and expiry. Obvious anomalies ( 9 points out of $889,1.0 \%$ of data) were removed before analysis, but the remaining data were representative of the entire set. Type IV Sum of Squares was used to take into account the removal of these data points. A post-hoc Tukey HSD test was performed to assess groupings between temperatures and expiries.

ANOVA was carried out on intrinsic viscosity data and GC-MS peaks identified as m-cresol and phenol, and their correlation with ex- piry of sample, using OriginLab 2015. A critical p-value of 0.05 was used to test for significance.

\section{Results}

Initial experiments were performed to ascertain the temperature-dependent behaviour of nine clinically available insulins. Dynamic light scattering (DLS) was used as a fast and reliable method to determine the hydrodynamic radius (radius of hydrated molecule assuming a perfect sphere) of each insulin preparation.

\subsection{Dynamic light scattering}

\subsubsection{Initial screening}

Fig. 2 exhibits the screening of nine structurally different insulins at three different temperatures using DLS to measure hydrodynamic size. Native insulins are presented along the top row (a-c), fast-acting analogues in the middle row $(\mathrm{d}-\mathrm{f})$ and slow-acting analogues in the bottom row $(\mathrm{g}-\mathrm{i})$.

Human recombinant insulin (a) presented a hydrodynamic radius of $1.8 \mathrm{~nm}$ regardless of the temperature in the measured range. Bovine (b), Porcine (c), Aspart (d) and Lispro (f) all had radii of $2.3 \mathrm{~nm}$, also independent of temperature. Glulisine (e) was larger at $2.6 \mathrm{~nm}$. Glargine (g) and Degludec (i) yielded the smallest radii of the measured insulins, with values closer to $1.0-1.2 \mathrm{~nm}$.

Depending upon temperature, IDet (h) ranged between 2.3 and $3.1 \mathrm{~nm}$, and from visual analysis appears to significantly decrease in size with increased temperature (Fig. 2(h)). The significance of this difference was confirmed using t-tests $(\mathrm{p}=0.013,=0.014,=0.00056$ for 20:28, 28:37, 20:37, respectively). Consequently, addi-
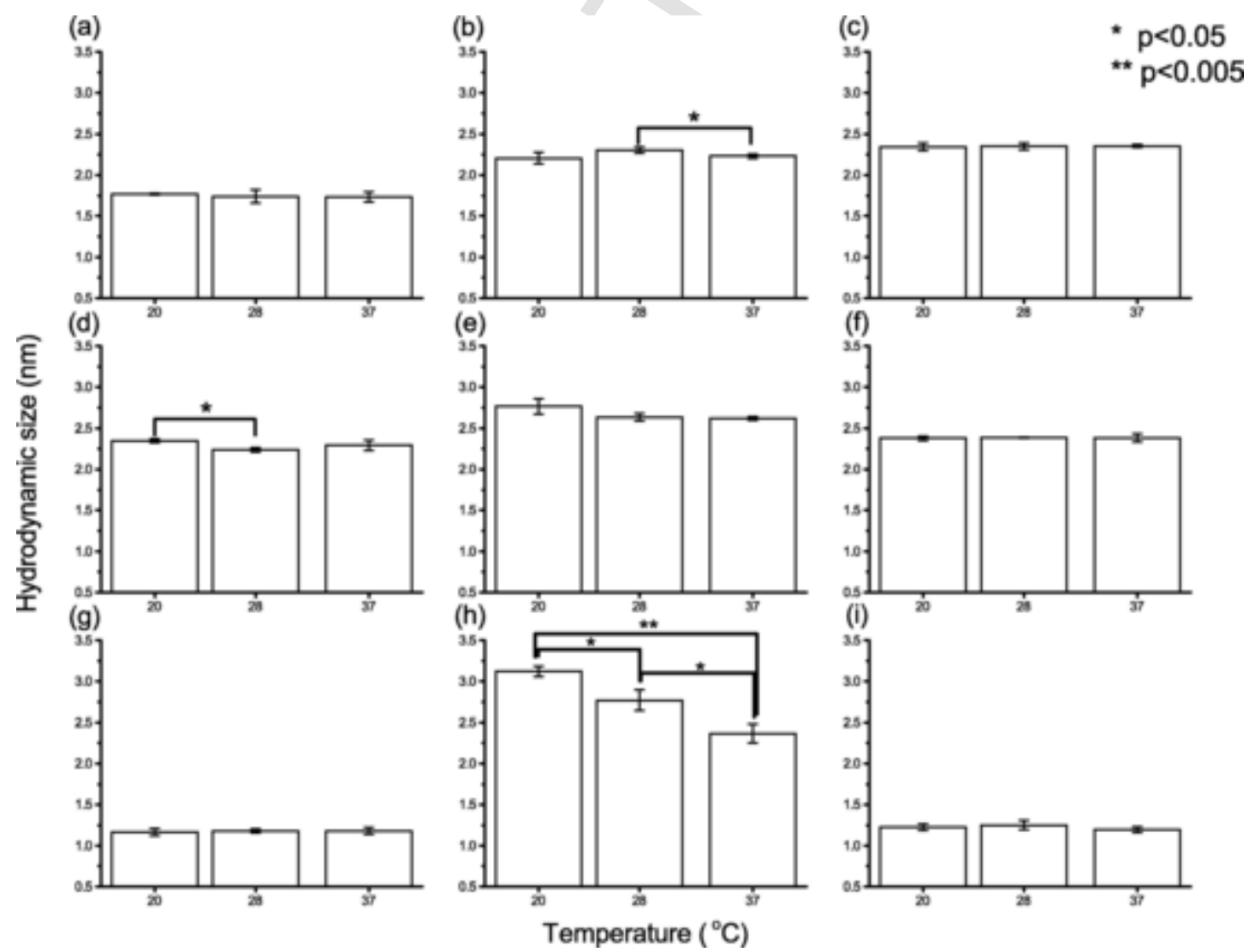

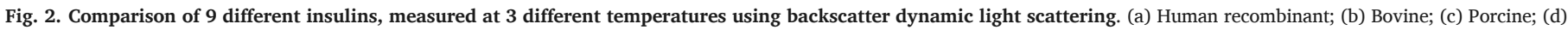

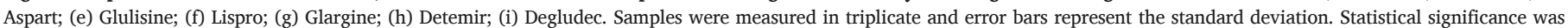
measured using a 2-tailed $t$-test, where $*$ denotes $\mathrm{p}<0.05$ and ${ }^{* *} \mathrm{p}<0.005$. 
tional experimentation was carried out on IDet to investigate this phenomenon.

\subsubsection{Multiple regression analysis of IDet}

Results of more detailed analysis of IDet have been presented in Fig. 3 , showing hydrodynamic size against temperature, increasing and decreasing, with subplots representing the 5 expiries. A clear trend can be observed in the unexpired (2020) IDet, where there was an inverse relationship between size $\left(\mathrm{r}_{\mathrm{H}}\right)$ and temperature. The insulin behaviour was also dependent on the direction from which the temperature equilibrium was obtained, either from heating (ascending) or cooling (descending). As the system cooled, the size increased, however not to the original point obtained when the system was heated. This is most apparent at $20{ }^{\circ} \mathrm{C}$, where the size is either $9 \mathrm{~nm}$ or $6 \mathrm{~nm}$, a 1.5 fold difference.

The same trend can be observed for the other expired insulins, but with $20{ }^{\circ} \mathrm{C}$ values decreasing with increased expiry. $37{ }^{\circ} \mathrm{C}$ values do not appear to consistently change with expiration, but descending temperatures that start at $37^{\circ} \mathrm{C}$ tend to be higher than the same temperature from ascending only in expired samples.

The statistical analysis is represented graphically in Fig. 4 and summarised in Table 1.

All components and interactions, including second-order (Temperature*Direction*Expiry), yielded statistical significance. This suggests that the direction of temperature (from heating or cooling), the temperature itself and sample expiration all co-interacted with each other.

\subsection{Sedimentation velocity}

Sedimentation velocity analysis of IDet, unexpired, showed a complex, heterogeneous system, as shown in Fig. 5. The main component was a peak at $3.12 \mathrm{~S}$, likely to be the hexamer, constituting $66 \%$ of the concentration distribution. Three further peaks at 5.52, 7.10 and 8.99 represented $21 \%, 7 \%$ and $2 \%$ of the total concentration respec- tively, and are likely to be multi-oligomers of hexameric IDet. A small fraction $(0.83 \mathrm{~S}, 4 \%$ ) was also present and is likely to be IDet monomer.

\subsection{Intrinsic viscosity}

Intrinsic viscosities are plotted in Fig. 6. For the unexpired (2020) IDet sample, there is a general increasing, but statistically insignificant, trend with intrinsic viscosity starting at $4.2 \mathrm{~mL} / \mathrm{g}$ at $20^{\circ} \mathrm{C}$ and increasing to $5.6 \mathrm{~mL} / \mathrm{g}$ at $37^{\circ} \mathrm{C}\left(\mathrm{F}_{1,3}=1.580, \mathrm{p}=0.298\right)$. The 1 year expired (2017) IDet sample shows much greater standard errors in measurement and an overall decreasing trend $\left(\mathrm{F}_{1,3}=0.743, \mathrm{p}=0.452\right)$. Intrinsic viscosities were, however, approximately the same as unexpired, apart from two high-error measurements at $\sim 12 \mathrm{~mL} / \mathrm{g}$. IDet 2016 (2 year expired) displayed a similar increasing trend to the unexpired formulation $\left(\mathrm{F}_{1,3}=3.860, \mathrm{p}=0.144\right)$, although intrinsic viscosities, as well as standard errors, were generally higher, reaching as high as at $7 \mathrm{~mL} / \mathrm{g}$. IDet 2015 exhibited small standard errors and intrinsic viscosities and were generally higher than the equivalent 2016 samples, as high as $12.5 \mathrm{~mL} / \mathrm{g}$ at $37^{\circ} \mathrm{C}$, and the same overall increasing trend is still present $\left(F_{1,3}=5.225, p=0.106\right)$. The most expired sample, IDet 2013, exhibited the strongest trend and ANOVA suggests that it was statistically significant $\left(\mathrm{F}_{1,3}=11.80, \mathrm{p}=0.041\right)$.

\subsection{Gas chromatography coupled to hard-ionisation mass spectrometry}

GC-MS analysis yielded two main elution peaks, identified in all measured samples, at $35.8 \mathrm{~min}$ and $37.1 \mathrm{~min}$ as phenol and m-cresol, respectively. Identification was performed through hard-ionisation spectra cross-referenced with the NIST library. Their relative area-under-curve peak percentages are shown in Fig. 7.

Statistical significance of component percentage (phenol and $\mathrm{m}$-cresol), measured against expiry, was measured using ANOVA. Both components indicate a small positive slope (phenol: $\mathrm{F}_{1,2}=0.2196$, $\mathrm{p}=0.69$. m-cresol: $\mathrm{F}_{1,2}=8.128, \mathrm{p}=0.10$ ).

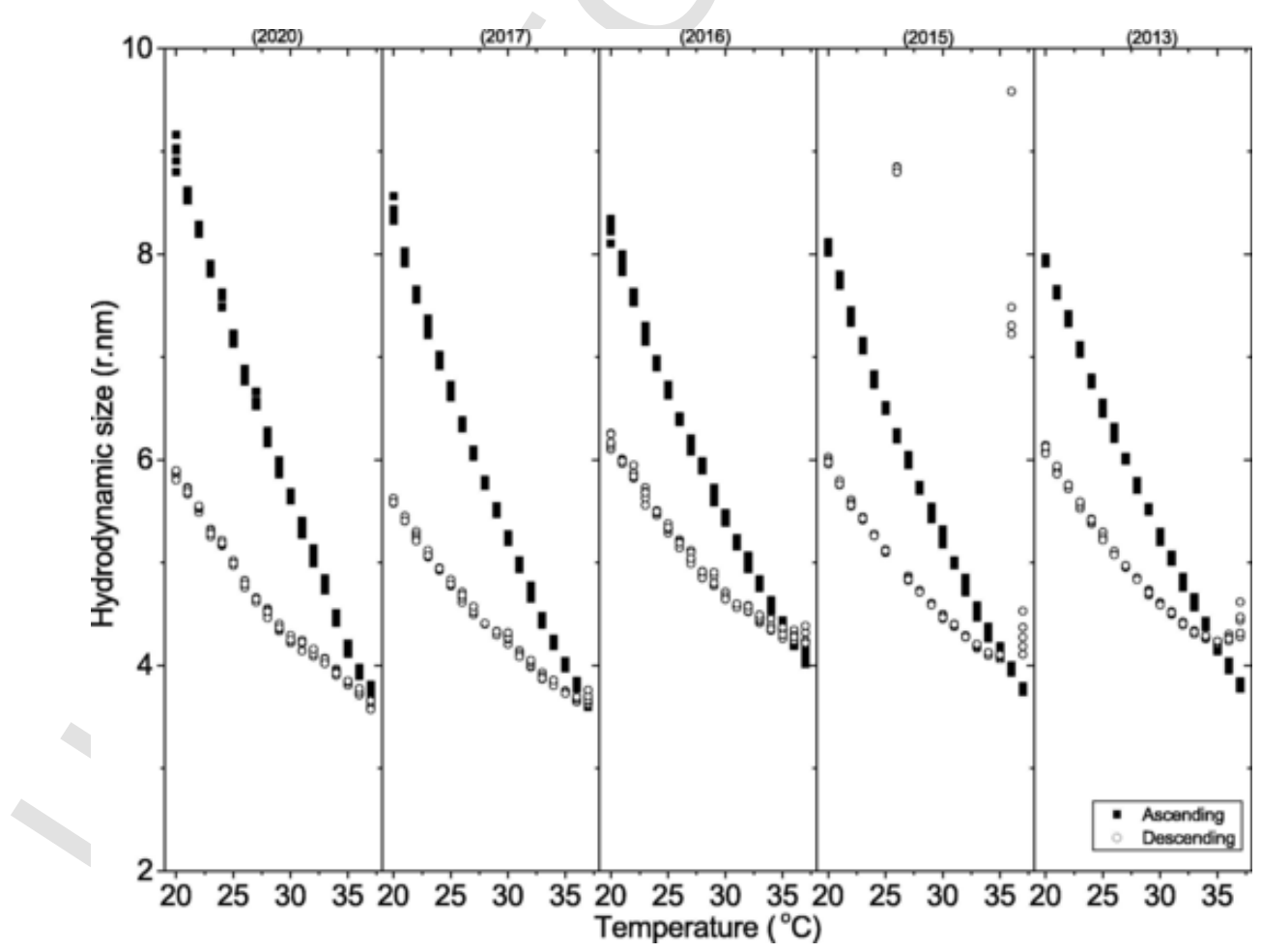

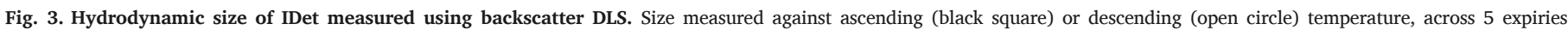
$(2020 \rightarrow 2013$, left to right). 5 replicates at each temperature are shown in each plot. 


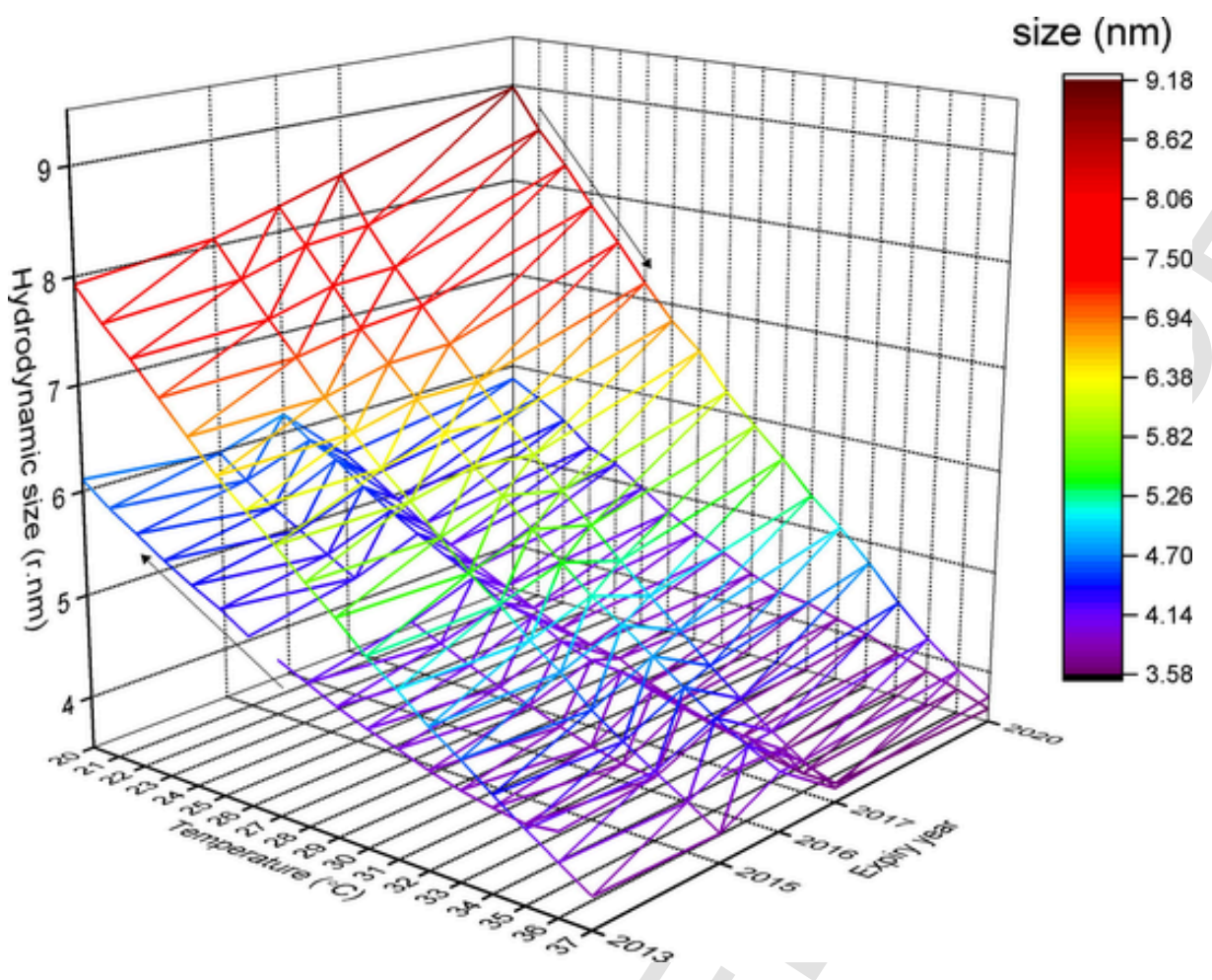

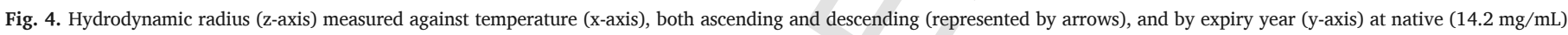
concentration.

Table 1

Summary output of multiple regression general linear model for IDet temperature dependence $\left(20-37^{\circ} \mathrm{C}\right)$. Size was tested against temperature, direction (ascending/descending temperature) and expiry (2013, 2015, 2016, 2017, 2020). Only first and second-order interactions are shown; all main effects were statistically significant $(\mathrm{p}<0.001)$.

\begin{tabular}{lll}
\hline Component & F-statistic & Significance \\
\hline Direction*Temperature & $\mathrm{F}_{17,711}=4601$ & $\mathrm{p}<0.001$ \\
Direction*Expiry & $\mathrm{F}_{4,711}=2895$ & $\mathrm{p}<0.001$ \\
Temperature*Expiry & $\mathrm{F}_{68,711}=57.40$ & $\mathrm{p}<0.001$ \\
Direction*Temperature*Expiry & $\mathrm{F}_{62,711}=26.51$ & $\mathrm{p}<0.001$ \\
\hline
\end{tabular}

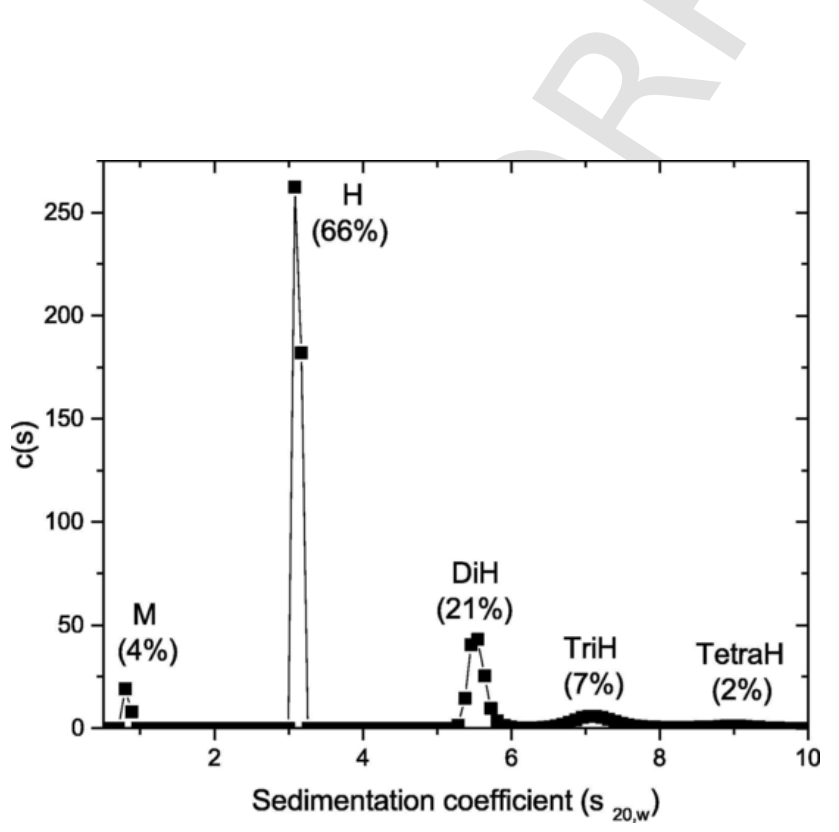

Fig. 5. c(s) distribution of sedimentation velocity data for IDet (unexpired).
Other peaks were also present, but only represented $\sim 10 \%$ of eluted signal. These included a series of peaks eluting at 11.8-12.2 min all identified as benzene, representing $\sim 5 \%$ of overall signal. This is likely a degradation product of phenol and m-cresol. Another peak at $13.6 \mathrm{~min}$ was identified as p-/o-xylene representing $\sim 2 \%$ of total signal. Again, this is likely a product of phenol and m-cresol degradation. All other major peaks were variations of plausible degradation products (i.e. small, phenol compounds) of phenol and m-cresol.

\section{Discussion}

\subsection{DLS}

Dynamic light scattering was used as a rapid and accurate technique to screen all nine insulins for temperature dependence. The sizes obtained were consistent with experiments performed under similar conditions, although only at $20.0{ }^{\circ} \mathrm{C}$ [1].

Differences in sizes between temperatures were assessed using student T-tests. The majority of non-IDet samples were deemed insignificant ( $\mathrm{p}>0.05$ ) however statistical significance was observed in insulins Bovine $28: 37^{\circ} \mathrm{C}(\mathrm{p}=0.05)$ and Aspart $20: 28{ }^{\circ} \mathrm{C}(\mathrm{p}=0.01)$. In these instances, the low number of repeats $(n=3)$ suggests the possibility of a high type I error (false positive), corroborated by statistical insignificance between Bovine $20: 28{ }^{\circ} \mathrm{C}, 20: 37^{\circ} \mathrm{C}$, and Aspart $28: 37^{\circ} \mathrm{C}, 20: 37{ }^{\circ} \mathrm{C}$. However, the significance found in IDet could not be ignored, considering $\mathrm{p}<0.05$ for all 3 pairs, and was evidence enough to continue the investigation more thoroughly. Upon thorough investigation of IDet, the same pattern was observed.

The temperature dependence can be explained thermodynamically that an increase in energy into the system will cause the components to change from low-energy states (multi-hexameric species [14] into higher-energy states. In this instance, higher-energy states probably represent lower-order stoichiometric species such as monomers and dimers [8]. Thus, an average of these states would appear to reduce in size. The difference in whether the system was heated or cooled im- 


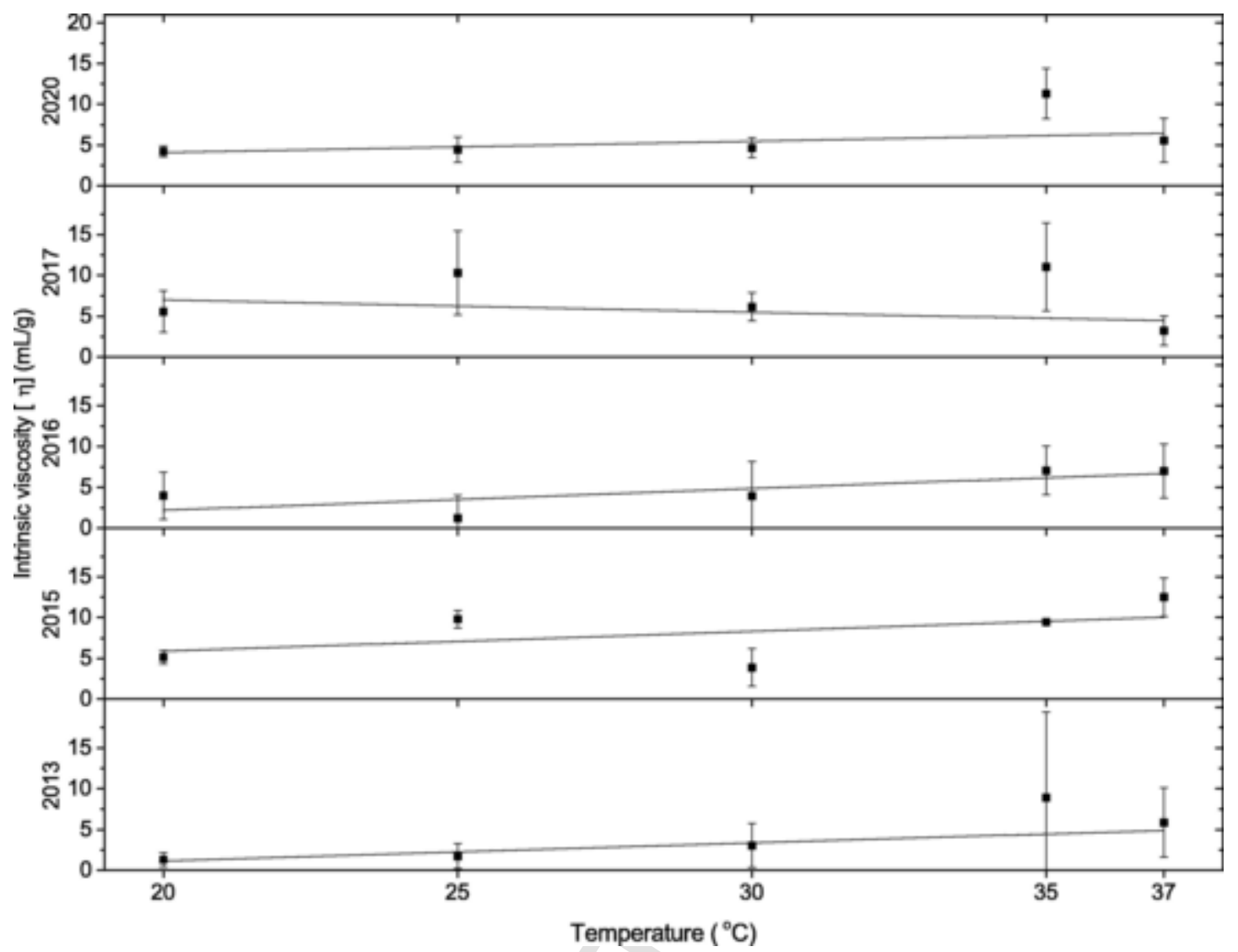

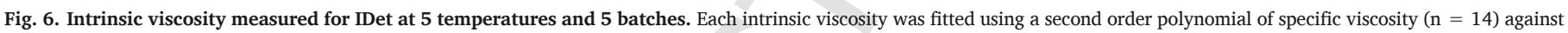
5 concentrations $(n=5)$. Error bars represent standard error of regression. A linear regression, weighted by error bars, represents ANOVA statistical analysis.

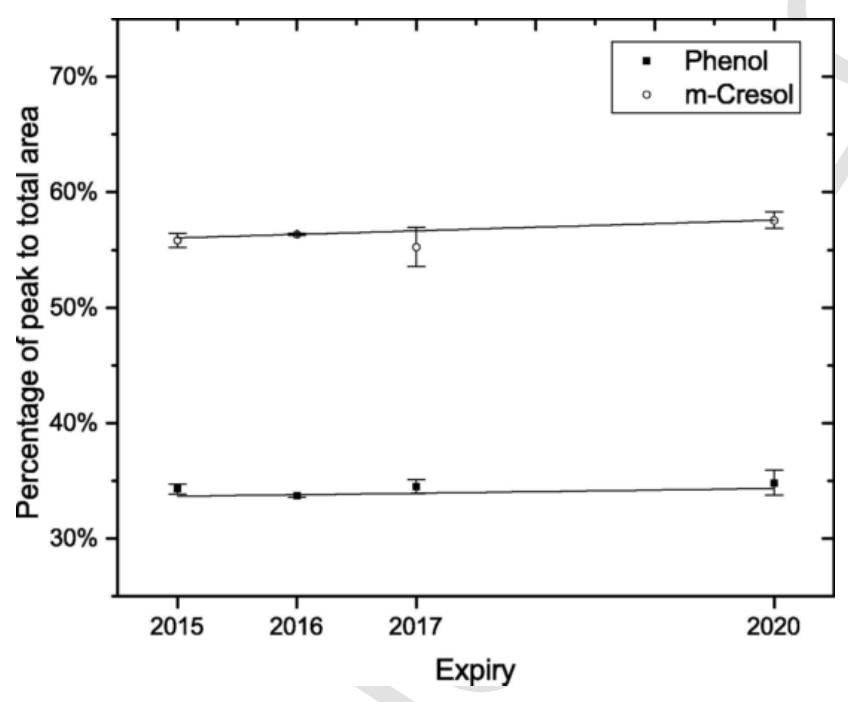

Fig. 7. Percentage of peak present after SPME-GC-MS volatile extraction from headspaces of IDet preparations. Error bars represent standard deviation based on duplicate measurements. Line of best fit is a linear regression weighted for error bars.

pacting the size of IDet can also be explained by the rate of this physical reaction. A slow reaction would mean that, although the physical temperature of the vial would have equilibrated, the energy states of IDet assemblies would take more time to achieve the original state. Furthermore, this would also explain the second-order interaction between direction, temperature and size as an increased temperature would increase the rate of this reaction. The reaction kinetics of this stoichiometric change cannot be determined from this experiment alone but is the subject of further investigation.

Expiration dependence was also significant from MANOVA analysis. This indicates that a change in structure, past expiry, might impact insulin functionality. Additionally, this change would increase with further expiration and this may be a justification for the manufacturer's suggested expiration date. The exact mechanism, however, remains unclear based on DLS analysis alone.

\subsection{Sedimentation velocity}

Results from the sedimentation velocity indicated a complex formation of IDet assemblies, ranging from monomer (0.9S, $5900 \mathrm{Da})$ up to icositetramer/tetra-hexamer $(9.0 \mathrm{~S}, \sim 140 \mathrm{kDa})$. However the majority of material was in the hexameric state $(3.1 \mathrm{~S}, \sim 35.5 \mathrm{kDa})$, with multi-hexameric species forming successively. This phenomenon has been well-documented in acylated insulin analogues $[10,25]$. However, ultimately, it is the monomeric form which actively induces the hypoglycaemic response, and explains the slow-acting nature of this analogue.

\subsection{Viscosity}

Intrinsic viscosity was also measured to assess both temperature dependence and expiry dependence. The majority of calculated values were consistent with a globular protein of close-to-spherical conformation [9]. Some values, however, were calculated to be as high as $12.5 \mathrm{~mL} / \mathrm{g}$, a value consistent with intrinsic viscosity values of heated bovine serum albumin reported by Masuelli \& Gassmann [19] but were also associated with a large standard error, and thus it is difficult 
to draw conclusions on these values. There were also values that were observed to be lower than $2.5 \mathrm{~mL} / \mathrm{g}$. It is likely that the measurement of solvent viscosity introduced a degree of error in the calculation, however the same formulation/value would be used for all subsequent measurements and therefore the trends in intrinsic viscosity against temperature are still valid.

The overall increase in intrinsic viscosity with higher temperature suggests the insulin assemblies either decrease in overall sphericity or increase in volume [9]). On first observation, this appears to contradict the results obtained from DLS, where higher temperature led to a decrease in size of all IDet samples. However, it is important to note that both trends are taken from averages of a complex system of stoichiometries, and that the two methods measure different forms of averages. Light scattering is heavily biased towards larger particles [26], whereas the average obtained from viscometry is value closer to what could be considered a weighted average of species. It is known that IDet forms a wide variety of species from monomeric to multi-hexameric [1]. It is possible that increasing the temperature caused a reduction in the number of multi-hexameric and monomeric species, dissociating or associating (respectively) into hexameric forms; which would elicit the observed results. However, without extensive distribution-based methods to probe this further, it would only be possible to speculate on this behaviour.

\subsection{Mass-spectrometry}

Phenol and m-cresol are excipients critical to the stability of the insulin hexamer [3], and present in most clinically available insulins; the exception being Insuman Infusat (Sanofi). This is somewhat surprising as phenol, and to a lesser extent m-cresol, are carcinogenic compounds, yet diabetic patients are injecting these formulations multiple times a day.

The dose of these compounds per injection are relatively low. $\mathrm{LD}_{50}$ for phenol is $140 \mathrm{mg} / \mathrm{kg}$ and for m-cresol is $242 \mathrm{mg} / \mathrm{kg}$ [5]. With up to $3.5 \mathrm{mg} / \mathrm{mL}$ of phenol/m-cresol per vial, vast quantities would need to be injected to achieve toxicity, however the long-term effects of multiple injections every day are still not fully understood.

The presence of excipient degradation products in IDet samples, as discovered with GC-MS, is not surprising, nor is the decrease in phenol and $\mathrm{m}$-cresol with increased expiration. Although the statistical analysis suggests that this is not significant, for m-cresol the level of significance was $p=0.10$, which is indicative of an effect even if it did not meet the 0.05 cut-off. Similar to the DLS screening statistical analysis, there may be a risk of type II error (false negative) based on the small repeat size $(n=2)$. Further replicates were not possible due to sample availability.

The potential depletion of these excipients would perhaps explain the behaviour observed in DLS and intrinsic viscosity measurements where expiration caused an effect in both. For the MANOVA analysis, in which interactions between the components were observed, it is likely that the ability to stabilise the hexamer would have follow-on implications for the reaction kinetics (temperature dependence, temperature direction dependence).

One of the limitations of using SPME-GC-MS was that the relative percentages of the two excipients are representative of diluted samples, as the very high concentrations of phenol and m-cresol are over the limits for SPME. Therefore, their actual concentration may also impact their partitioning in the gas phase.

\subsection{Impact on patient therapy}

The use of insulin involves several changes in environmental temperature. Vials of insulin remain between 2 and $8{ }^{\circ} \mathrm{C}$ while stored at pharmacies and $\sim 5^{\circ} \mathrm{C}$ in patient refrigerators (assuming, of course, pa- tient adherence to storage instructions). Patients then inject the insulin, perhaps with a brief warming period (vial rolled between hands), where the bolus sits as a depot in the sub-cutaneous layer. It can be assumed that insulin entering the bloodstream reach $37^{\circ} \mathrm{C}$ but the temperature state in-bolus remains uncertain. The equilibrium exchange between stoichiometric forms has been conclusively shown to be impacted by the temperature and therefore the rate of absorption of monomers into the bloodstream is reduced.

It is still unclear what mechanism underlies the temperature-dependence functional difference between IDet and the other clinically relevant insulins. However, this is currently under investigation by our research team and will be the topic of future publications. It is critical to discover this mechanism as temperature dependence is directly linked to clinical behaviour and patient therapy. With further understanding, temperature dependence may lead to the development of future generations of peptide-based therapies with greater clinical efficacy.

\section{Conclusion}

Nine clinically-available insulins were assessed for their temperature dependence, but only IDet showed a significant reduction in apparent size. Upon further investigation, an effect was observed that the temperature history/direction of heating/cooling impacts the apparent size, which was confirmed with viscometry (measuring intrinsic viscosity. It was posited that the temperature impacted the stoichiometric ratio, measured through sedimentation velocity, with the difference in temperature history suggesting a slow rate of reaction.

Furthermore, expiration was also probed for its effect on size and excipient concentration for IDet compared to in-date preparation. Expired samples (1-5 years out of date) showed a smaller size at $20^{\circ} \mathrm{C}$ (ascending) and a proportional disparity between values at $37^{\circ} \mathrm{C}$ (descending).

Although an explanation for IDet's behaviour was made, the reason the same phenomenon was not observed in the other eight insulins is still unclear and is the focus of further investigation.

\section{Acknowledgements}

The authors thank the Independent Diabetes Trust (IDDT) for their sponsorship of this research (Grant: ID/TT025272/1). We are also grateful for the help of Charlotte Moody.

\section{Author Contributions}

O.B. was involved in design, data acquisition, interpretation of data and drafting the manuscript.

R.B.G. was involved in the conception, design, data acquisition, data analysis, interpretation and drafting \& revision of the script.

V.D. performed data acquisition, interpretation of data and drafting the manuscript.

S.I.J., P. G-A., S.H., G.A., F.F., I.F., P.S.M., A.M. and S.E.H. were involved in interpretation of data and revision of the script.

G.G.A. was involved in the conception, design, interpretation and drafting \& revision of the script.

\section{Declaration of Competing Interest}

R.B.G. and S.I.J. are funded by IDDT. G.G.A. is a non-executive director of IDDT.

No other authors express any competing interests.

\section{References}

[1] G G Adams, A Meal, P S Morgan, Q E Alzahrani, H Zobel, R Lithgo, M S Kok, D T M Besong, S I Jiwani, S Ballance, Characterisation of insulin analogues therapeutically available to patients, PLoS One 13 (2018) e0195010. 
[2] J Brange, S Havelund, P Hougaard, Chemical stability of insulin. 2. Formation of higher molecular weight transformation products during storage of pharmaceutical preparations, Pharm. Res. 9 (1992) 727-734.

[3] J Brange, L Langkjaer, Chemical stability of insulin. 3. Influence of excipients, formulation, and pH, Acta Pharm. Nord. 4 (1992) 149-158.

[4] C R Cantor, P R Schimmel, Biophysical Chemistry, Part II: Techniques for the Study of Biological Structure and Function, WH Freeman and Company, San Francisco, 1980.

[5] S Chadwick, Ullmann's Encyclopedia of Industrial Chemistry, Wiley, 2000.

[6] C Chandler, C M Gryniewicz, T Pringle, F Cunningham, Insulin temperature and stability under simulated transit conditions, Am. J. Heal. Pharm. 65 (2008) 953-963.

[7] T M Chapman, C M Perry, Insulin detemir: a review of its use in the management of type 1 and 2 diabetes mellitus, Drugs 64 (2004) 2577-2595.

[8] K Gast, A Schüler, M Wolff, A Thalhammer, H Berchtold, N Nagel, G Lenherr, G Hauck, R Seckler, Rapid-Acting and Human Insulins: Hexamer Dissociation Kinetics upon Dilution of the Pharmaceutical Formulation, Pharm. Res. 34 (2017) 2270-2286.

[9] S E Harding, The intrinsic viscosity of biological macromolecules. Progress in measurement, interpretation and application to structure in dilute solution, Prog. Biophys. Mol. Biol. 68 (1997) 207-262.

[10] S Havelund, A Plum, U Ribel, I Jonassen, A Vølund, J Markussen, P Kurtzhals, The mechanism of protraction of insulin detemir, a long-acting, acylated analog of human insulin, Pharm. Res. 21 (2004) 1498-1504.

[11] K Hermansen, P Fontaine, K K Kukolja, V Peterkova, G Leth, M-A Gall, Insulin analogues (insulin detemir and insulin aspart) versus traditional human insulins (NPH insulin and regular human insulin) in basal-bolus therapy for patients with type 1 diabetes, Diabetologia 47 (2004) 622-629.

[12] T Hoeg-jensen, Design of Insulin Variants for Improved Treatment of Diabetes, in: K J Jensen (Ed.), Peptide and Protein Design for Biopharmaceutical Applications, John Wiley \& Sons, 2009, pp. 249-286.

[13] P D Home, Plasma insulin profiles after subcutaneous injection: how close can we get to physiology in people with diabetes? Diabetes, Obes. Metab. 17 (2015) $1011-1020$.

[14] I Jonassen, S Havelund, T Hoeg-Jensen, D B Steensgaard, P O Wahlund, U Ribel, Design of the novel protraction mechanism of insulin degludec, an ultra-long-acting basal insulin, Pharm. Res. 29 (2012) 2104-2114, doi:10.1007/ s11095-012-0739-z.

[15] W Kozicki, P Q Kuang, An alternative method for evaluation of intrinsic viscosity, Can. J. Chem. Eng. 74 (1996) 429-432.
[16] P Kurtzhals, S Havelund, I B Jonassen, B Kiehr, U Ribel, J Markussen, Albumin binding and time action of acylated insulins in various species, J. Pharm. Sci. 85 (1996) 304-308, doi:10.1021/js950412j.

[17] K J Lipska, M M Parker, H H Moffet, E S Huang, A J Karter, Association of initiation of basal insulin analogs vs neutral protamine hagedorn insulin with hypoglycemia-related emergency department visits or hospital admissions and with glycemic control in patients with type 2 diabetes, Jama 320 (2018) 53-62.

[18] A-V Madenidou, P Paschos, T Karagiannis, A Katsoula, E Athanasiadou, K Kitsios, E Bekiari, D R Matthews, A Tsapas, Comparative Benefits and Harms of Basal Insulin Analogues for Type 2 Diabetes, Ann Intern Med 169 (2018) 165-174.

[19] M A Masuelli, J Gassmann, Intrinsic viscosity bovine serum albumin in aqueous solutions: temperature influence on Mark-Houwink parameters, Adv. Physicochem. Prop. Biopolym. (Part 1). Bentham Sci. Publ. UAE (2017) 28-59.

[20] Novo-Nordisk, 2015. Levemir(r) patient information sheet.

[21] A Oliva, J Fariña, M Llabrés, Influence of temperature and shaking on stability of insulin preparations: degradation kinetics, Int. J. Pharm. 143 (1996) 163-170.

[22] H B Olsen, N C Kaarsholm, Structural effects of protein lipidation as revealed by LysB29-myristoyl, des (B30) insulin, Biochemistry 39 (2000) 11893-11900.

[23] A Philis-Tsimikas, G Charpentier, P Clauson, G M Ravn, V L Roberts, B Thorsteinsson, Comparison of once-daily insulin detemir with NPH insulin added to a regimen of oral antidiabetic drugs in poorly controlled type 2 diabetes, Clin. Ther. 28 (2006) 1569-1581.

[24] P Schuck, Size-distribution analysis of macromolecules by sedimentation velocity ultracentrifugation and lamm equation modeling, Biophys. J. 78 (2000) 1606-1619.

[25] D B Steensgaard, G Schluckebier, H M Strauss, M Norrman, J K Thomsen, A V Friderichsen, S Havelund, I Jonassen, Ligand-controlled assembly of hexamers, dihexamers, and linear multihexamer structures by the engineered acylated insulin degludec, Biochemistry 52 (2013) 295-309, doi:10.1021/bi3008609.

[26] J Stetefeld, S A Mckenna, T R Patel, Dynamic light scattering: a practical guide and applications in biomedical sciences, Biophys. Rev. 409-427 (2016), doi:10.1007/s12551-016-0218-6.

[27] W O Storvick, H J Henry, Effect of storage temperature on stability of commercial insulin preparations, Diabetes 17 (1968) 499-502.

[28] B van Noorden, J L Knopp, J G Chase, A subcutaneous insulin pharmacokinetic model for insulin Detemir, Comput. Methods Programs Biomed. 178 (2019) 1-9.

[29] A K Varanko, A Chilkoti, Molecular and Materials Engineering for Delivery of Peptide Drugs to Treat Type 2 Diabetes, Adv. Healthc. Mater. (2019) 1801509. 